\title{
Quality of Reporting in Upper Gastrointestinal Endoscopy: Effect of a Simple Audit Intervention
}

\author{
Pedro Lisboa-Gonçalves $^{a}$ Diogo Libânio $^{a, b}$ Joana Marques-Antunes ${ }^{a}$ \\ Mário Dinis-Ribeiro ${ }^{a, b}$ Pedro Pimentel-Nunes ${ }^{a-c}$ \\ ${ }^{a}$ Center for Health Technology and Services Research, Faculty of Medicine, University of Porto, Porto, Portugal; \\ ${ }^{b}$ Gastroenterology Department, Portuguese Oncology Institute of Porto, Porto, Portugal; ' Department of Surgery \\ and Physiology, Faculty of Medicine, University of Porto, Porto, Portugal
}

\section{Keywords}

Esophagogastroduodenoscopy · Quality audit · Software registration · Performance measure

\section{Abstract}

Background and Aim: In contrast to colonoscopy, there are few studies regarding upper gastrointestinal (UGI) endoscopy reporting its quality and ways of improving it. Quality audits are recommended, but their influence on the abovementioned quality is not well studied. Our aim was to evaluate the quality of UGI endoscopy reports and assess the effect of a simple audit intervention on UGI endoscopy reporting quality. Methods: This was a prospective study in a tertiary referral center, including the evaluation of 1,000 consecutive reports of UGI endoscopies before an audit intervention and 250 after. The reports were analyzed according to performance measures defined by three experienced gastroenterologists. Results: Before the intervention, $51.8 \%$ of the incomplete endoscopies did not present any justification for its incompleteness and $88.1 \%$ of lesions were correctly described. Overall, $64.1 \%$ of the reports were considered as being of high quality. After the audit intervention, follow-up recommendation ( 53.4 vs. $80.8 \%, p=0.001$ ), cor- rect lesion description ( 88.1 vs. $95.8 \%, p=0.001)$, and correct segment description ( 92.2 vs. $96.4 \%, p=0.020$ ) improved significantly. The rate of unjustified incomplete endoscopies decreased significantly ( 51.8 vs. $28.9 \%, p=0.010$ ). The highquality endoscopy rate improved $13.9 \%$ after the intervention $(p<0.001)$. Both specialists and residents improved with the audit intervention with a similar percentage of improvement in the high-quality endoscopy rate (13.9 vs. $13.4 \%$ ). Conclusions: A simple audit intervention is a good way to improve the quality of reporting of UGI endoscopy, independently of degree and experience. Some of the performance measure accomplishments may depend on the software used by the endoscopy centers and it should be a priority to optimize it.

(C) 2018 Sociedade Portuguesa de Gastrenterologia Published by S. Karger AG, Basel

\section{Qualidade dos Relatórios na Endoscopia Digestiva Alta: Efeito de uma Intervenção com Auditoria}

Palavras Chave

Endoscopia digestiva alta · Auditoria de qualidade . Software de registo $\cdot$ Parâmetros de qualidade

\section{KARGER}

E-Mail karger@karger.com www.karger.com/pjg
(C) 2018 Sociedade Portuguesa de Gastrenterologia Published by S. Karger AG, Basel

Karcer

0 pen access

This article is licensed under the Creative Commons AttributionNonCommercial-NoDerivatives 4.0 International License (CC BYNC-ND) (http://www.karger.com/Services/OpenAccessLicense) Usage and distribution for commercial purposes as well as any distribution of modified material requires written permission.
Dr. Pedro Lisboa-Gonçalves

Faculty of Medicine, University of Porto

Al. Prof. Hernâni Monteiro

PT-4200-319 Porto (Portugal)

E-Mail pedro.silgon@gmail.com 


\section{Resumo}

Introdução: Em contraste com a colonoscopia, há poucos estudos relativos à qualidade dos relatórios da endoscopia digestiva alta (EDA) e métodos para a sua melhoria. Auditorias de qualidade são recomendadas, mas a sua influência na qualidade da EDA não está suficientemente estudada. O objetivo foi avaliar a qualidade dos relatórios de EDA, bem como do efeito de uma intervenção com auditoria. Métodos: Estudo prospetivo realizado num centro terciário de referência. $O$ estudo incluiu a análise de 1,000 relatórios de EDA consecutivas realizadas antes de uma intervenção e de 250 após. Os relatórios foram analisados de acordo com parâmetros de qualidade definidos por três gastrenterologistas com experiência. Resultados: Antes da intervenção, 51.8\% das endoscopias incompletas não continham qualquer justificação para o facto e $88.1 \%$ das lesões foram corretamente descritas. No total, $64.1 \%$ dos relatórios foram considerados de alta qualidade. Após a intervenção, a recomendação de follow-up (53.4\% vs. $80.8 \%, p=0.001)$, descrição correta das lesões (88.1\% vs. $95.8 \%, p=0.001$ ) e descrição correta de todos os segmentos (92.2\% vs. $96.4 \%, p=0.020$ ) aumentaram significativamente. A percentagem de endoscopias incompletas não justificadas diminuiu significativamente (51.8\% vs. $28.9 \%, p=0.010)$. A percentagem de EDA de alta qualidade aumentou $13.9 \%$ após a intervenção $(p<$ 0.001). Tanto especialistas como internos melhoraram com a intervenção, verificando-se um aumento similar na percentagem de EDA de alta qualidade (13.9\% vs. 13.4\%). Conclusões: Uma intervenção baseada numa auditoria é uma boa forma de melhorar a qualidade da documentação de EDA independentemente do grau ou experiência. O cumprimento de parâmetros de qualidade pode depender do software utilizado e como tal o seu melhoramento deve ser uma prioridade.

() 2018 Sociedade Portuguesa de Gastrenterologia Publicado por S. Karger AG, Basel

\section{Introduction}

Upper gastrointestinal (UGI) endoscopy or esophagogastroduodenoscopy (EGD) is the gold standard for the diagnosis of UGI diseases and is also a powerful tool for minimally invasive therapeutic procedures.

Several widely accepted performance measures were developed to assess colonoscopy quality $[1,2]$ and several studies exist evaluating the quality of colonoscopy in routine practice $[3,4]$. However, for EGD there are only a few studies assessing quality measures [5], particularly

Quality of Reporting in Upper

Gastrointestinal Endoscopy of the reporting. Moreover, only very recently were performance measures for EGD published by the European Society of Gastrointestinal Endoscopy (ESGE) [6]. This lack of performance measures, which lasted much longer than for colonoscopy, may have been affecting EGD quality over the years. In fact, a recent meta-analysis reported that gastric cancer missing rates are around $10 \%$ [7], superior to the $6 \%$ documented for colorectal cancer [8].

Quality audit benefits include an opportunity for endoscopic units and their members to assess their current status in terms of procedure quality, providing an opportunity and motivation to improve it [9]. However, due to a lack of quality indicators until recently, there are few relevant studies assessing EGD quality. Very recently, a similarly designed study tried to evaluate improvement after a training program [10]. Nevertheless, it is not yet sufficiently described if quality audits have practical effects on the quality and if those depend on degree and experience.

Therefore, this study aimed to evaluate the quality of EGD and EGD reports in a tertiary center and to assess the effect of a simple audit intervention on improving quality.

\section{Methods}

\section{Study Design and Selection of Cases}

This was a prospective study performed at the Instituto Português de Oncologia do Porto, Portugal, a tertiary oncology referral center. Consecutive patients submitted to EGD in the year of 2012 were included and their EGD reports were analyzed in a total of 1,000 reports included. These 2012 reports were made based on an Access program (Microsoft, USA) that required manual photo recording in independent photo software. In January 2013, the endoscopy reporting software changed (SiiMA gastro, First Global, Portugal), allowing automatic photo documentation. Even though the software was different, the only major change was in photo documentation, with free text for reporting and the only obligatory information being patient and endoscopist identification. An additional 55 reports of 2015 were analyzed and compared with the reports done in 2012 to verify the effect of the software on quality indicators. In October 2016, the results of the 2015 quality analysis were presented to all the gastroenterologists performing EGD in the Gastroenterology Department during a clinical meeting. Only the overall analysis and the comparison between specialists and residents were presented, without personalized analysis. General recommendations concerning reporting quality were given and all gastroenterologists were informed that subsequent periodic evaluations would take place. The first 250 EGD reports of 2017 were then similarly analyzed. The gastroenterologists were not informed that there would be another evaluation starting in 2017 . No exclusion criteria were defined a priori. 
Table 1. Performance measures and their criteria of accomplishment

\begin{tabular}{|c|c|}
\hline Performance measure & Description \\
\hline Indication & Presence of indication for the UGI endoscopy \\
\hline Chromoendoscopy use & Utilization of chromoendoscopy \\
\hline Completeness of endoscopy & $\begin{array}{l}\text { Description of the second portion of the duodenum or efferent loop (of operated } \\
\text { stomachs) }\end{array}$ \\
\hline $\begin{array}{l}\text { Justification for an incomplete } \\
\text { endoscopy }\end{array}$ & Presence of justification for an incomplete examination \\
\hline Segment description & $\begin{array}{l}\text { Esophagus: reference to the esophagus and esophagogastric junction } \\
\text { Stomach: reference to fundus, body, incisures, pyloric antrum, pylorus } \\
\text { Duodenum: reference to bulb and second portion of the duodenum } \\
\text { Operated stomach: reference to stump, anastomosis, and loop }\end{array}$ \\
\hline Photo documentation & Presence of $>8$ photographs in the endoscopy report \\
\hline Clarity on the number of biopsy containers & Clear reference to the number of biopsy containers \\
\hline Number of vials & At least 2 different containers for lesions of gastritis/gastropathy \\
\hline Correct lesion description & $\begin{array}{l}\text { Use of standardized disease classifications: } \\
\text { Esophagitis: Los Angeles classification } \\
\text { Barrett's esophagus: Prague classification } \\
\text { Strictures: location, extension and permeability to endoscope } \\
\text { Erosions/peptic ulcers: size, location, borders, and bed; Forrest classification in case of } \\
\text { bleeding ulcers } \\
\text { Superficial lesions: Paris classification } \\
\text { Gastritis/gastropathies: location, subtype (atrophic, eritematous, etc.) } \\
\text { Subepithelial lesions: location, size } \\
\text { Polyps: location, subtype, size } \\
\text { Operated stomachs: stump, anastomosis, loop }\end{array}$ \\
\hline Final conclusion & Presence and concordance of conclusion with the description \\
\hline Follow-up & Presence of recommended follow-up in the report \\
\hline Abbreviations & Absence of abbreviations in the report \\
\hline Comprehensibility & Comprehensibility of the report by two final-year medical students \\
\hline
\end{tabular}

Variable Definition and Analysis Performed

This study (conceived by P.L.G., P.P.-N., and M.D.-R.) was started before the performance measures defined by the ESGE were published. Thus, three expert gastroenterologists (P.P.-N., M.D.-R., D.L.) were consulted in order to select the criteria to define high-quality EGD reporting that should be included in this study. In the case of disagreements, a consensus was reached, and only the performance measures that were accepted by the three gastroenterologists were included (Table 1).

All but 1 performance measure (comprehensibility) were objective and retrieved directly from the report. Comprehensibility of the report was classified by two final-year medical students that analyzed the reports. A minimum of 8 photographs (esophagus: gastroesophageal junction; stomach: cardia in retroflexed view; fundus/body in retroflexed view; body in forward view; angulus/ incisura; antrum; bulb, and finally the second portion of the duodenum) plus lesion photographs were considered as criteria for adequate photo documentation.
The proportion of reports that did not accomplish each performance measure before and after the intervention was assessed. Additionally, a subgroup analysis was performed according to the degree of specialization of the gastroenterologist: resident or specialist. Three reports were excluded from this analysis due to a lack of information about the operator.

An additional analysis was performed according to specific indications or findings on UGI endoscopy: esophagitis, Barrett's esophagus, strictures, gastritis/gastropathy, erosions/ulcers, superficial lesions, subepithelial lesions, polyps, and operated stomach. In this analysis, the performance measures of photo documentation and the use of standardized disease-related terminology were assessed. In the case of gastritis/gastropathy, the use of 2 or more biopsy containers as recommended was also evaluated.

Finally, the proportion of high-quality EGD reporting was calculated. EGD reporting was defined by the same three experienced gastroenterologists as high-quality if all the following criteria were met: presence of indication, complete examination or a justified 
Table 2. Raw numbers and percentages of specialists, residents, and all gastroenterologists concerning the accomplishment of performance measures before (2012) and after (2017) the intervention

\begin{tabular}{|c|c|c|c|c|c|c|c|c|c|c|}
\hline & \multicolumn{3}{|l|}{ Specialists } & \multicolumn{3}{|l|}{ Residents } & \multirow{2}{*}{$\begin{array}{l}\text { S vs. R } \\
(2012) \\
p\end{array}$} & \multicolumn{3}{|l|}{ Total } \\
\hline & 2012 & 2017 & $p$ & 2012 & 2017 & $p$ & & 2012 & 2017 & $p$ \\
\hline Indication & $543(87.3)$ & $144(92.9)$ & 0.051 & $375(100)$ & $88(92.6)$ & $<0.001$ & $<0.001$ & $919(91.9)$ & $232(92.8)$ & 0.637 \\
\hline Chromoendoscopy use & $4(0.6)$ & $10(6.5)$ & $<0.001$ & $19(5.1)$ & $15(15.8)$ & $<0.001$ & $<0.001$ & $23(2.3)$ & $25(10.0)$ & $<0.001$ \\
\hline Complete endoscopy & $526(84.6)$ & $133(85.8)$ & 0.700 & $279(74.4)$ & $80(84.2)$ & 0.044 & $<0.001$ & $808(80.8)$ & $213(85.2)$ & 0.108 \\
\hline $\begin{array}{l}\text { Unjustified incomplete } \\
\text { endoscopy }\end{array}$ & $47(49.5)$ & $8(36.4)$ & 0.267 & $52(54.2)$ & $3(18.8)$ & 0.009 & 0.516 & $99(51.8)$ & $11(28.9)$ & 0.010 \\
\hline $\begin{array}{l}\text { Correct segment } \\
\text { description }\end{array}$ & $565(90.8)$ & $151(97.4)$ & 0.006 & $354(94.4)$ & $90(94.7)$ & 0.898 & 0.042 & $922(92.2)$ & $241(96.4)$ & 0.020 \\
\hline Photo documentation & $222(35.7)$ & $143(92.3)$ & $<0.001$ & $136(36.3)$ & $89(93.7)$ & $<0.001$ & 0.854 & $358(35.8)$ & $232(92.8)$ & $<0.001$ \\
\hline Number of photos $>8$ & $0(0.0)$ & $108(75.5)$ & & $0(0.0)$ & $69(77.5)$ & & & $0(0.0)$ & $177(76.3)$ & \\
\hline Biopsy & $178(28.6)$ & $51(32.9)$ & 0.295 & $153(40.8)$ & $32(33.7)$ & 0.205 & $<0.001$ & $332(33.2)$ & $83(33.2)$ & 1.000 \\
\hline Clear number of vials & $120(67.8)$ & $25(49.0)$ & 0.014 & $97(63.4)$ & $22(68.8)$ & 0.566 & 0.401 & $217(65.6)$ & $47(56.6)$ & 0.130 \\
\hline Lesions & $467(75.1)$ & $131(84.5)$ & 0.013 & $338(90.1)$ & $83(87.4)$ & 0.431 & $<0.001$ & $808(80.8)$ & $214(85.6)$ & 0.079 \\
\hline Correct lesion description & $399(85.3)$ & $124(94.7)$ & 0.004 & $314(92.9)$ & $81(97.6)$ & 0.112 & 0.001 & $713(88.2)$ & $205(95.8)$ & 0.001 \\
\hline Conclusion & 615 (98.9) & $151(97.4)$ & 0.170 & $368(98.1)$ & $95(100)$ & 0.180 & 0.335 & $986(98.6)$ & $246(98.4)$ & 0.812 \\
\hline Correct conclusion & $588(95.6)$ & $148(98.0)$ & 0.172 & $350(94.9)$ & $90(94.7)$ & 0.964 & 0.585 & $941(95.3)$ & $238(96.7)$ & 0.334 \\
\hline Follow-up & $256(41.2)$ & $123(79.4)$ & $<0.001$ & $276(73.6)$ & $79(83.2)$ & 0.053 & $<0.001$ & $534(53.4)$ & $202(80.8)$ & $<0.001$ \\
\hline Abbreviations & $47(7.6)$ & $5(3.2)$ & 0.054 & $55(14.7)$ & $2(2.1)$ & 0.001 & $<0.001$ & $104(10.4)$ & $7(2.8)$ & $<0.001$ \\
\hline Complications & $15(2.4)$ & $1(0.6)$ & 0.166 & $16(4.3)$ & $1(1.1)$ & 0.134 & 0.102 & $31(3.1)$ & $2(0.8)$ & 0.042 \\
\hline Comprehensibility & $576(92.6)$ & $151(97.4)$ & 0.029 & $338(90.1)$ & $94(98.9)$ & 0.005 & 0.171 & $916(91.6)$ & $245(98.0)$ & $<0.001$ \\
\hline High-quality endoscopy & $387(62.2)$ & $118(76.1)$ & 0.001 & $254(67.7)$ & $77(81.1)$ & 0.011 & 0.075 & $641(64.1)$ & $195(78.0)$ & $<0.001$ \\
\hline
\end{tabular}

S, specialists; R, residents. Values in italics indicate statistically significant differences $(p<0.05)$.

incomplete one, correct lesion description (when present), correct segment description, presence of a correct conclusion, presence of 2 or more containers when lesions of gastritis present, and complete comprehensibility.

\section{Statistical Analysis}

IBM Statistic Software - IPSS, Microsoft Office Excel 2007, and Graphpad software were used in the data collection and statistical analysis. Descriptive statistics include number and proportions for categorical variables. Comparisons between groups were performed with the $\chi^{2}$ test, and a $p$ value $<0.05$ was considered statistically significant.

\section{Results}

\section{Before the Intervention (2012)}

From the data retrieved from 1,000 reports in 2012, $64.1 \%$ were considered high-quality reports of EGD, with the remaining failing to meet at least 1 of the performance measures defined for the high-quality EGD reporting analysis. Overall, an indication for the examination was present in $91.9 \%$, the examination was complete in $80.8 \%$, and a conclusion was reported in $98.6 \%$ (Table 2). How- ever, $51.8 \%$ of the reports did not include the reason for an incomplete procedure, and adequate photo documentation was only present in $35.8 \%$ of the procedures. Presence of indication, correct segment description, correct lesion description, presence of follow-up, and absence of abbreviations were all significantly higher in residents when compared with specialists (Table 2). Despite this, no significant differences were found in the percentage of high-quality reports between the two groups (62.2 vs. $67.7 \%, p=0.075$ ).

The lesion-based analysis outlined superficial lesions as the most common incorrectly described lesions (38.5\%), while subepithelial lesions were most often correctly described (92.9\%). Photo documentation was particularly low in strictures (16.7\%), while gastritis/gastropathy was the more frequently photo-documented condition (57.6\%). In gastritis/gastropathy, when biopsies were taken, 2 or more containers were used in $90.3 \%$ of the cases. Significant differences between specialists and residents were found in the performance measure of 2 or more containers in the case of gastritis/gastropathy lesions ( 84.2 vs. $100 \%, p=0.012$ ), photo documentation of stricture lesions (25.4 vs. $9.9 \%, p=0.013$ ), and correct polyp description ( 75.0 vs. $96.2 \%, p=0.027)$. 
Fig. 1. Comparison between the percentages of accomplishment of the performance measures of chromoendoscopy use, unjustified incomplete endoscopy, correct segment description, correct lesion description, follow-up presence, and highquality endoscopy. * Statistically significant difference $(p<0.05)$.

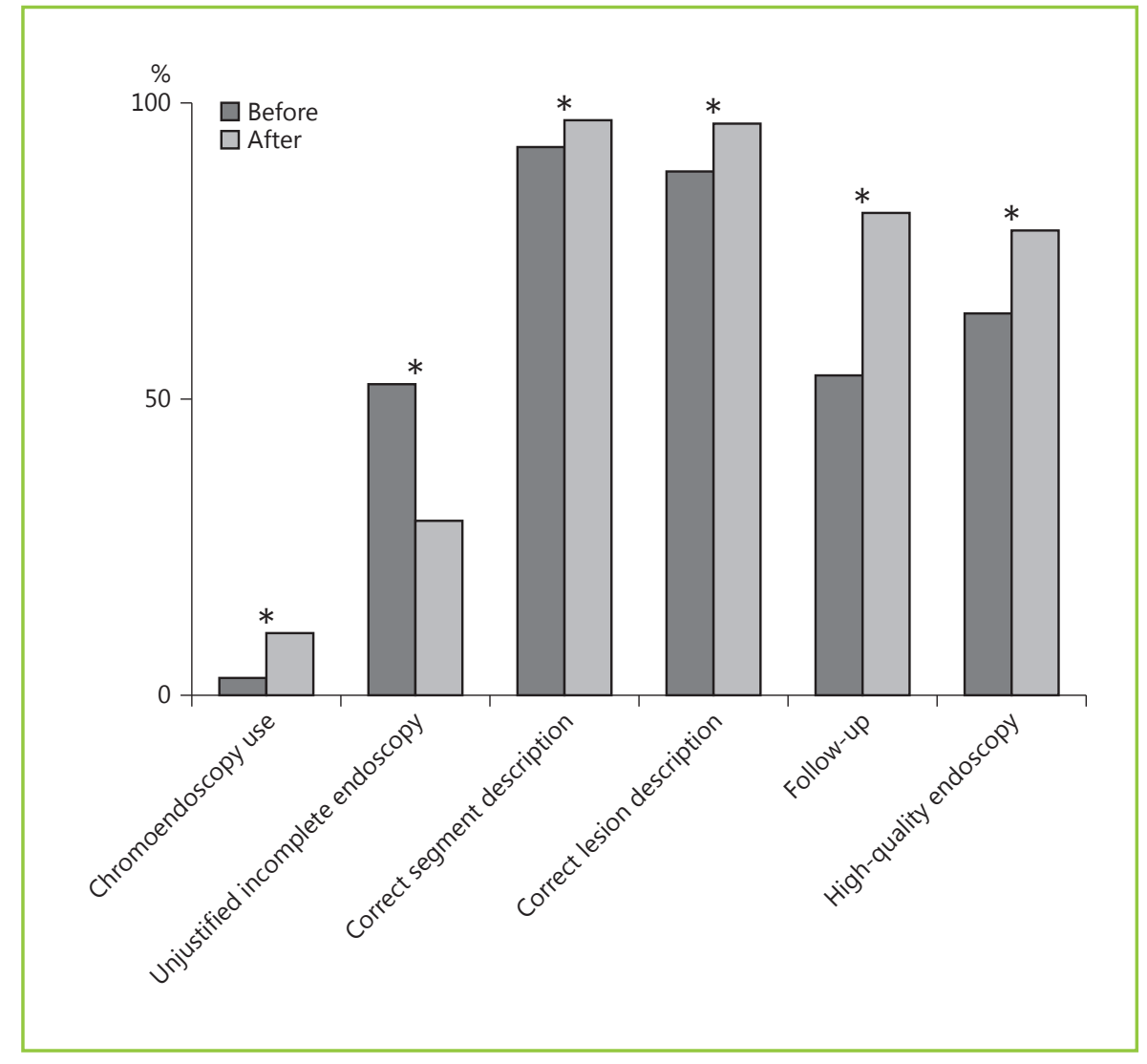

Before the Intervention, after Changing the Software (2015)

Overall, the 55 endoscopy reports showed similar results to the 2012 reports. Significant differences between the 2012 and 2015 reports, with worse results in 2015, were found in the performance measures of indication presence (91.9 vs. $78.2 \%, p<0.001)$, correct segment description ( 92.2 vs. $70.9 \%, p<0.001)$, correct conclusion presence (95.3 vs. $81.5 \%, p<0.001$ ), abbreviations (10.4 vs. $21.8 \%, p=0.008$ ), and comprehensibility (91.6 vs. $78.2 \%, p=0.001)$. The only parameter that improved in 2015 was photo documentation ( 35.8 vs. $87.3 \%, p<0.001$ ). However, no significant differences were found in the high-quality endoscopy reporting rate (64.1 vs. $63.6 \%$, $p=0.944)$.

\section{After the Intervention: Overall Results}

The comparison between the reports from 2012 and 2017 showed an overall significant increase in almost all performance measures and a significant increase in the rate of high-quality reporting ( 64.1 vs $78.0 \%, p<0.001$ ) (Fig. 1). An increase was also found in the rates of accom- plishment of the performance measures of indication presence and concordance of conclusion with description, but the difference was not statistically different. On the other hand, the presence of clear information on the number of containers/vials (65.6 vs $56.6 \%$ ) and the presence of a conclusion (98.6 vs. $98.4 \%$ ) were the only performance measures that showed a decrease after the intervention, although not statistically significant (Table 2).

The lesion-based analysis (Table 3 ) showed a significant increase of correctly described lesions in reports with gastritis/gastropathy ( $90.7 \mathrm{vs.} 100 \%, p=0.007)$ and superficial lesions ( 61.5 vs. $94.7 \%, p=0.010)$. A nonsignificant increase was also found in all other lesions, with the exception of strictures where a nonsignificant decrease was found ( 90.3 vs. $90.0 \%, p=0.977$ ).

\section{After the Intervention: Specialists versus Residents}

Both residents and specialists improved their accomplishment of the performance measures evaluated (Fig. 2). Nevertheless, the presence of clear information about the number of bottles significantly decreased in the specialist group ( 67.8 vs. $49.0 \%, p=0.014$ ), while there was a trend 
Table 3. Raw numbers and percentages for each performance measure accomplishment by all gastroenterologists before and after the intervention if the lesion was present in the report

\begin{tabular}{|c|c|c|c|c|}
\hline \multirow[t]{2}{*}{ Lesion } & \multirow[t]{2}{*}{ Performance measure } & \multicolumn{2}{|c|}{ Gastroenterologists, $n(\%)$} & \multirow[t]{2}{*}{$p$} \\
\hline & & before & after & \\
\hline \multirow[t]{2}{*}{ Barrett's esophagus } & Correct lesion description & $10 / 12(83.3)$ & $4 / 4(100)$ & 0.383 \\
\hline & Photo documentation & $6 / 12(50.0)$ & $4 / 4(100)$ & 0.074 \\
\hline \multirow[t]{2}{*}{ Erosions/peptic ulcers } & Correct lesion description & $53 / 66(8.3)$ & $9 / 9(100)$ & 0.143 \\
\hline & Photo documentation & $35 / 66(53.0)$ & 9/9 (100) & 0.007 \\
\hline \multirow[t]{3}{*}{ Gastritis/gastropathy } & 2 or more containers & $96 / 106(90.5)$ & $30 / 30(100.0)$ & 0.093 \\
\hline & Correct lesion description & $127 / 140(90.7)$ & $56 / 56(100)$ & 0.018 \\
\hline & Photo documentation & $81 / 140$ (57.9) & $56 / 56(100)$ & 0.000 \\
\hline \multirow[t]{2}{*}{ Esophagitis } & Correct lesion description & $68 / 78(87.2)$ & $18 / 18(100)$ & 0.108 \\
\hline & Photo documentation & $36 / 78(46.2)$ & $16 / 18(88.9)$ & 0.001 \\
\hline \multirow[t]{2}{*}{ Strictures } & Correct lesion description & $130 / 144(90.3)$ & $9 / 10(90.0)$ & 0.977 \\
\hline & Photo documentation & $24 / 144(16.7)$ & 9/10 (90.0) & 0.000 \\
\hline \multirow[t]{2}{*}{ Subepithelial lesion } & Correct lesion description & 92/101 (92.9) & $18 / 18(100)$ & 0.245 \\
\hline & Photo documentation & $36 / 101(35.4)$ & $16 / 18(88.9)$ & 0.000 \\
\hline \multirow[t]{2}{*}{ Superficial lesion } & Correct lesion description & $16 / 26(61.5)$ & $18 / 19(94.7)$ & 0.010 \\
\hline & Photo documentation & $12 / 26(46.2)$ & $15 / 19(78.9)$ & 0.001 \\
\hline \multirow[t]{2}{*}{ Polyps } & Correct lesion description & $49 / 58(84.5)$ & $16 / 17(94.1)$ & 0.304 \\
\hline & Photo documentation & $31 / 58(53.4)$ & $15 / 17(88.2)$ & 0.010 \\
\hline \multirow[t]{2}{*}{ Operated stomach } & Correct lesion description & $133 / 156(85.3)$ & $38 / 43(88.4)$ & 0.603 \\
\hline & Photo documentation & $67 / 156(42.9)$ & $41 / 43(95.3)$ & 0.000 \\
\hline
\end{tabular}

Values in italics indicate statistically significant differences $(p<0.05)$.

towards an improvement in this performance measure in the resident group (63.4 vs. $68.8 \%, p=0.556$ ). On the other hand, the rate of indication presence on the report decreased in residents (100 vs. $92.6 \%, p<0.001)$ and increased in specialists ( 87.3 vs. $92.9 \%, p=0.051$ ). The performance measures correct segment description, clear information about the number of containers used when biopsies were taken, correct lesion description, and follow-up recommendation increased significantly in specialists, as opposed to residents. On the other hand, the performance measures abbreviations and comprehensibility improved significantly in residents, but not in specialists. The performance measures chromoendoscopy use and photo documentation as well as the rate of highquality endoscopy reporting improved significantly in both specialists and residents, with an increase of 13.9 and $13.4 \%$, respectively (Table 2).

The lesion-based analysis showed more significant improvements in specialists than residents. Photo documentation, except for Barrett's esophagus and polyps, as well as the description of superficial lesions improved significantly in specialists. Similarly, the photo documentation of gastritis/gastropathy, strictures, subepithelial lesions, superficial lesions, polyps, and operated stomachs improved significantly in residents. There were no significant improvements in the lesion description of any lesion.

\section{Discussion}

To our knowledge, this study is one of the first studies evaluating the quality of UGI endoscopy and the effect of an intervention on the quality of the procedure. We found that the rate of high-quality endoscopy reporting was $64.1 \%$ in 2012 , increasing to $78.0 \%$ in 2017 after a brief intervention about quality parameters.

The majority of the performance measures evaluated in this study are similar to those recently recommended by the ESGE guidelines [6], such as photo documentation 


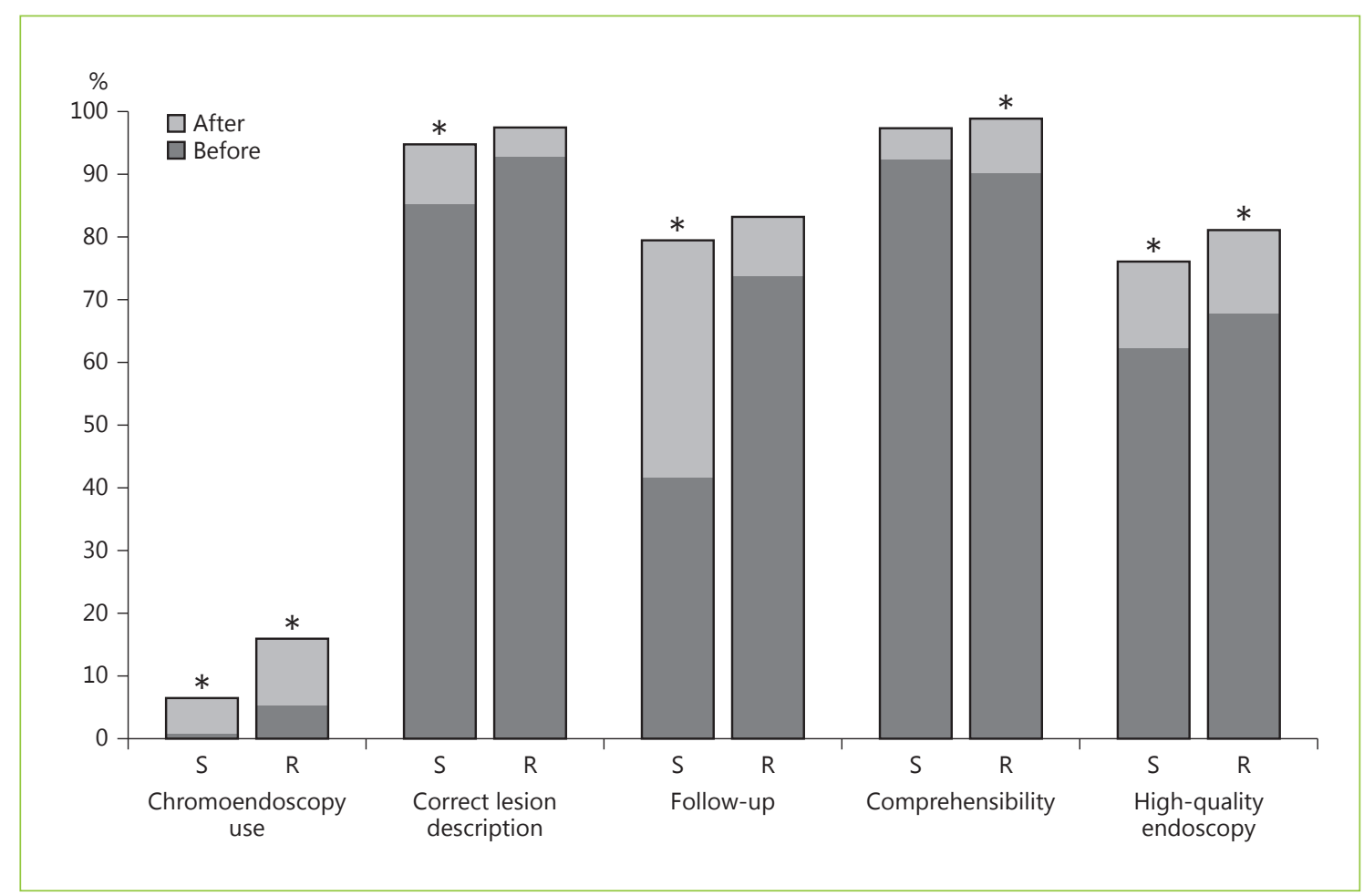

Fig. 2. Rates of accomplishment of the performance measures of the specialists and residents before and after the intervention. S, specialists; R, residents. * Statistically significant difference $(p<0.05)$.

or the use of standardized disease-related terminology, even though this study was initiated before the publication of the ESGE guidelines. Other performance measures present in the ESGE guidelines were also considered important to evaluate, but they were not included in this study, since they could not be retrieved from the endoscopy reports (mainly due to the software used at our institution). This was the case for all time-related measures or the evaluation of fasting instructions. It is also important to note that additional performance measures (not present in the guidelines) were also evaluated in this study, because they were considered good quality indicators by the three experienced gastroenterologists, and perhaps these performance measures should be taken into account in future guidelines. As an example, although not being considered in the guidelines, other studies consider the presence of an indication and conclusion in the report to be essential in all endoscopic procedures $[11,12]$, and therefore we considered it essential to a high-quality EGD report. The use of standardized disease-related terminology, a performance measure included in the ESGE guidelines, was also included. Finally, the comprehensibility of the report by two final-year stu- dents was considered to be a key indicator, since doctors' understanding of the report is highly relevant.

We showed that with a simple intervention, the quality of EGD and its reporting can significantly improve. The analysis performed in 2012 showed that the accomplishment of some performance measures was lower than desirable, especially regarding the absence of justification for an incomplete examination and follow-up recommendations. With this intervention, the rate of highquality reporting improved by $13 \%$, and there was a marked improvement (from 88 to $96 \%$ ) in the use of standardized disease terminology, a key performance measure present in the guidelines. The rate of high-quality endoscopies after the intervention was $80 \%$, a value similar to the reported rate of high-quality colonoscopies [13]. We also found that the overall rate of high-quality endoscopy reporting was similar between residents and specialists and that the intervention resulted in a similar improvement in both groups in the rate of high-quality reporting. Moreover, not only the audit might have had a positive effect on reporting, but the fact that the endoscopists knew that periodic audits would be initiated might also have had a positive effect on the results. High-quali- 
ty colonoscopy, an area where several performance studies exist, is known for its importance in cancer prevention [14] but also for providing better patient experience and cost reduction [9], and efforts should be made to improve the quality in UGI endoscopy since it can also be associated with the improvement of those outcomes.

Our study has some limitations. First, the performance measures were retrieved only from endoscopy reports and did not include real-time relevant quality indicators such as lesion detection. Nevertheless, reporting is an essential part of the procedure, as important as the technical part of it and should not be underestimated. It is our understanding that a well-performed but not adequately reported procedure is still not a high-quality EGD. As previously stated, the software used in our institution limited some of the performance measures evaluated (e.g., timerelated indicators, sedation, and endoscope information). In contrast to what would be expected, the 2015 analysis showed no significant improvement in endoscopy reporting quality relative to 2012 . Actually, the significant differences found demonstrated a decrement in the rate of accomplishment of some performance measures, such as indication presence, correct segment description, concordance of conclusion with description, or comprehensibility. The exception was the rate of reports with photo documentation of the procedure, showing a sharp improvement of $51.8 \%$. This improvement is probably due to the software change, which made photo documentation easier and less time consuming. We cannot rule out that the natural development of health services and the increasing awareness of the importance of high-quality endoscopy reporting might have had a role in this improvement. However, since the results of 2015 were worse that the ones of 2012, it looks likely the audit was the most important factor for the increased quality of reporting. Despite this, it is important to highlight that this analysis included only 55 reports and consequently the precision of the results may be low. With this analysis we demonstrated that, other than photo documentation, no signifi- cant differences were evident between the quality of endoscopy reporting of 2012 and 2015, supported by the similar rate of high-quality endoscopy rates in both analyses. Because of this similarity, we chose to compare the 2012 analysis with the 2017 analysis, since the number of reports collected was much higher (and if any we are underestimating the effect of the intervention).

The results of this study suggest that an intervention may increase the quality of the procedure, although it should be complemented with other measures. One of them is certainly software facilities, as recommended by ESGE [15], with results demonstrated both in this study (with the photo documentation increase of 2015 compared to 2012) and in a recent study regarding colonoscopy quality [16]. Simple measures, such as an obligation to fill in key information or the utilization of a userfriendly, less time-consuming software, should be made a priority. We believe that changes in the software allowing an easier way to collect data (for instance, measuring the time of endoscopy by clicking on a button) and making some parameters obligatory will allow for a better endoscopy quality.

In conclusion, we demonstrated that a high number of UGI endoscopy reports can be considered of high quality, although some performance measures are not sufficiently accomplished, and that an intervention with gastroenterologists giving feedback about the results of a quality analysis seems to be a simple way of improving UGI endoscopy quality independently of degree or experience.

\section{Statement of Ethics}

This article was approved by Instituto Português de Oncologia do Porto.

\section{Disclosure Statement}

The authors declare no conflicts of interest.

\section{References}

1 Rembacken B, Hassan C, Riemann JF, et al: Quality in screening colonoscopy: position statement of the European Society of Gastrointestinal Endoscopy. Endoscopy 2012;44: 957-968.

$\checkmark 2$ Rex DK, Schoenfeld PS, Cohen J, et al: Quality indicators for colonoscopy. Am J Gastroenterol 2015;110:72-90.

Quality of Reporting in Upper

Gastrointestinal Endoscopy
Gavin DR, Valori RM, Anderson JT, et al: The national colonoscopy audit: a nationwide assessment of the quality and safety of colonoscopy in the UK. Gut 2013;62:242-249.

4 Lieberman DA, Faigel DO, Logan J, et al: Assessment of quality of colonoscopy reports: Results from a multi-center consortium. Gastrointest Endosc 2009;69:645-653.
5 Park WG, Shaheen NJ, Cohen J, et al: Quality indicators for EGD. Am J Gastroenterol 2015; 110:60-71.

6 Bisschops R, Areia M, Coron E, et al: Performance measures for upper gastrointestinal endoscopy: a European Society of Gastrointestinal Endoscopy (ESGE) Quality Improvement Initiative. Endoscopy 2016;48:843-864. 
7 Pimenta-Melo AR, Monteiro-Soares M, Libânio D, et al: Missing rate for gastric cancer during upper gastrointestinal endoscopy: a systematic review and meta-analysis. Eur J Gastroenterol Hepatol 2016;28:1041-1049.

8 Bressler B, Paszat LF, Chen Z, et al: Rates of new or missed colorectal cancers after colonoscopy and their risk factors: a populationbased analysis. Gastroenterology 2007;132: 96-1024.

$>9$ Rutter MD, Rees CJ: Quality in gastrointestinal endoscopy. Endoscopy 2014;46:526-528.
Córdova H, Sánchez-Montes C, DelgadoGuillena PG, et al: Quality indicators for esophagogastroduodenoscopy: a comparative study of outcomes after an improvement programme in a tertiary hospital. Gastroenterol Hepatol 2017;40:587-594.

11 Gurudu SR, Ramirez FC: Quality metrics in endoscopy. Gastroenterol Hepatol 2013;9: 228-233.

12 Beaulieu D, Barkun AN, Tinmouth J, et al: Endoscopy reporting standards. Can J Gastroenterol 2013;27:286-292.

13 Hadlock SD, Liu N, Gould M, et al: The quality of colonoscopy reporting in usual practice: are endoscopists reporting key data elements? Can J Gastroenterol Hepatol 2016; 2016:1929361.
14 Rex DK, Boland CR, Dominitz JA, et al: Colorectal Cancer screening: Recommendations for physicians and patients from the U.S. Multi-Society Task Force on Colorectal Cancer. Am J Gastroenterol 2017;11:1016-1030.

15 Bretthauer M, Aabakken L, Dekker E, et al: Requirements and standards facilitating quality improvement for reporting systems in gastrointestinal endoscopy: European Society of Gastrointestinal Endoscopy (ESGE) Position Statement. Endoscopy 2016;48:291-294.

16 Taveira F, Areia M, Elvas L, et al: Quality in colonoscopy: beyond the adenoma detection rate fever. GE Port J Gastroenterol 2017;24: 211-218. 